\title{
Excitation of Some Nitrogen-Like Ions: Calculations and Comparison with Measurements
}

\author{
O.B. Nadykto ${ }^{1}$, B.A. Nadykto ${ }^{2}$, A.B. Nadykto ${ }^{1}$ \\ ${ }^{1}$ Department of Applied Mathematics, Moscow State Technological University "STANKIN", RU-127055, Moscow, Russia \\ ${ }^{2}$ Russian Federal Nuclear Center - All-Russian Scientific Research Institute of Experimental Physics (RFNC-VNIIEF), Sarov, Nizhny \\ Novgorod Region, RU-607188, Russia
}

\begin{abstract}
Electronic energies of one-electron excited states $1 s^{2} 2 s^{2} 2 p^{2} n s{ }^{4} \mathrm{P}, 1 s^{2} 2 s^{2} 2 p^{2} n s^{2} \mathrm{P}, 1 s^{2} 2 s^{2} 2 p^{2} n p{ }^{4} S$,

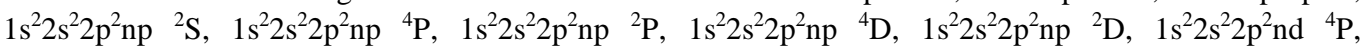
$1 s^{2} 2 s^{2} 2 p^{2} n d{ }^{2} \mathrm{P}, 1 s^{2} 2 s^{2} 2 p^{2} n d{ }^{4} \mathrm{D}, 1 s^{2} 2 s^{2} 2 p^{2} n d{ }^{2} \mathrm{D}, 1 s^{2} 2 s^{2} 2 p^{2} n d{ }^{4} \mathrm{~F}, 1 s^{2} 2 s^{2} 2 p^{2}$ nd ${ }^{2} \mathrm{~F}$ of nitrogen-like ions with $n=3-12$ and $\mathrm{Z}=7-50$ have been calculated. For all the aforementioned electronic configurations, finestructure levels have been determined for states with different total momentum J. The comparison of theoretical results with the available experimental data shows that theory and measurements agree well. In particular, relative accuracy of $10^{-4}$ has been achieved in the electronic energy of $\mathrm{N}$-like at $\mathrm{Z}>10$, while the typical deviation in the calculated fine-structure levels from experimental data is in the order of $10^{-2}$
\end{abstract}

\section{Introduction}

Knowledge of the energy levels of multiply charged ions with large nuclear charge $\mathrm{Z}$ is critically important for solving multiple emerging problems of plasma physics and astrophysics. Obtaining accurate energy levels is not an easy task because it requires accurate simultaneous accounting for relativistic and radiation effects. In the literature, there exist relevant quantum-mechanical studies concerning atomic energy levels and other related properties, for example [1-11]. The studies are dedicated to both the general theoretical approach [1-5] and specific methods for calculating energy levels of multielectron ions with varying Z [6-11]. A large fraction of complexity in getting accurate energy level is related to the fact that the Schrödinger equation is nonrelativistic, and, thus, the theoretical description of ions with $Z>>1$ requires obtaining relativistic corrections. The Dirac's approach [3] is considered by many to be more suitable for spectroscopic calculations. In both scenarios, taking into account the radiation effects is needed.

The commonly used handbooks [12]- [13] contain a compilation of experimental data on the energy levels of multiply charged ions with variable $Z$. Due to the complexity of the spectroscopic measurements of such ions, the amount of existing experimental data is quite small. On the other hand, direct quantum-mechanical simulations have very large, sometimes prohibitively high, computational costs and encounter significant difficulties related with the use of a number of approximations. The modified Bohr model [14] allows obtaining a large amount of data on the energies of various configurations of multiply charged ions with varying $\mathrm{Z}$ at nearly zeros computational costs. In this work, the modified Bohr model [14] is used to obtain energy levels of multiply charged $\mathrm{N}$-like ions. In particular, energies of one-electron excited states $1 s^{2} 2 s^{2} 2 p^{2} n s \quad{ }^{4} \mathrm{P}, \quad 1 s^{2} 2 s^{2} 2 p^{2} n s \quad{ }^{2} \mathrm{P}, \quad 1 s^{2} 2 s^{2} 2 p^{2} n p \quad{ }^{4} \mathrm{~S}$, $1 \mathrm{~s}^{2} 2 \mathrm{~s}^{2} 2 \mathrm{p}^{2} \mathrm{np} \quad{ }^{2} \mathrm{~S}, \quad 1 \mathrm{~s}^{2} 2 \mathrm{~s}^{2} 2 \mathrm{p}^{2} \mathrm{np} \quad{ }^{4} \mathrm{P}, \quad 1 \mathrm{~s}^{2} 2 \mathrm{~s}^{2} 2 \mathrm{p}^{2} \mathrm{np} \quad{ }^{2} \mathrm{P}$, $1 \mathrm{~s}^{2} 2 \mathrm{~s}^{2} 2 \mathrm{p}^{2} \mathrm{np} \quad{ }^{4} \mathrm{D}, \quad 1 \mathrm{~s}^{2} 2 \mathrm{~s}^{2} 2 \mathrm{p}^{2} \mathrm{np} \quad{ }^{2} \mathrm{D}, \quad 1 \mathrm{~s}^{2} 2 \mathrm{~s}^{2} 2 \mathrm{p}^{2}$ nd $\quad{ }^{4} \mathrm{P}$, $1 s^{2} 2 s^{2} 2 p^{2}$ nd $\quad{ }^{2} \mathrm{P}, \quad 1 \mathrm{~s}^{2} 2 \mathrm{~s}^{2} 2 \mathrm{p}^{2}$ nd $\quad{ }^{4} \mathrm{D}, \quad 1 \mathrm{~s}^{2} 2 \mathrm{~s}^{2} 2 \mathrm{p}^{2}$ nd ${ }^{2} \mathrm{D}$, $1 s^{2} 2 s^{2} 2 p^{2} n d{ }^{4} F, 1 s^{2} 2 s^{2} 2 p^{2}$ nd ${ }^{2} F$ of N-like ions with $n=3-$ 12 and $Z=7-50$ have been calculated and compared with available experimental data.

\section{Model and Method}

As for the ground state of boron-like and carbon-like ions [15], [16], [17], the energy of the ground state of nitrogen-like ions, 1s22s22p3, is described assuming the formation of a hybrid state of all (five) 2s22p3 outer electrons with the identical wave function parameter. The interaction potential of $2 \mathrm{~s}$ electrons and $2 \mathrm{p}$ electrons with internal $1 \mathrm{~s}$ electrons is described in the same way as in lithium-like ions [18-22]. The parameter of the hybridized wave function for ground state is determined by minimizing the sum of electronic energies of outer electrons. In this way, we get accurate energies of the ground state of ions with varying $Z$. An empirical parameter in this model is the screening coefficient of the nuclear charge due to the interaction of electrons in the 2s22p3 configuration. Excited states 1s22s2p4 are also considered as hybridized states with the identical wave function parameter of outer electrons.

e-mail: anadykto@gmail.com 


\section{Results and discussion}

After the accurate theoretical description of hybridized energy states of carbon-like ions is achieved, we begin modeling of multiple one-electron excitations of $\mathrm{N}$-like ions, where the outer electron is in the state with $n>2$. The ionic core $1 s^{2} 2 s^{2} 2 p^{2}$ yields multiple series of oneelectron excited states of $\mathrm{N}$-like ions $1 \mathrm{~s}^{2} 2 \mathrm{~s}^{2} 2 \mathrm{p}^{2} \mathrm{n} l$ with $\mathrm{n}>2$ and varying $l=0,1,2, \ldots, \mathrm{n}-1$. Different sets of similar series $1 \mathrm{~s}^{2} 2 \mathrm{~s} 2 \mathrm{p}^{3} \mathrm{nl}, 1 \mathrm{~s}^{2} 2 \mathrm{p}^{4} \mathrm{n} l$ are realized in the case, when the carbon-like core is in excited $1 s^{2} 2 s 2 p^{3}$ or $1 s^{2} 2 p^{4}$ states. The parameters for calculating the energy of oneelectron excited states of nitrogen-like ions are given in Table 1.

Table 1. Parameters of one-electron excited states of Nlike ions

\begin{tabular}{|c|c|c|c|c|c|}
\hline State & SIGM3 & $\mathrm{A}_{13}$ & $\mathrm{~B}_{13}$ & $\mathrm{~A}_{23}$ & $\mathrm{~B}_{23}$ \\
\hline \multicolumn{6}{|c|}{ Third shell } \\
\hline $1 \mathrm{~s}^{2} 2 \mathrm{~s}^{2} 2 \mathrm{p}^{2}\left({ }^{3} \mathrm{P}\right) n \mathrm{~s}^{4} \mathrm{P}$ & 0.0 & 0.8045 & 0.15 & 0.359 & 0.135 \\
\hline $1 \mathrm{~s}^{2} 2 \mathrm{~s}^{2} 2 \mathrm{p}^{2}\left({ }^{3} \mathrm{P}\right) n \mathrm{~s}^{2} \mathrm{P}$ & 0.0 & 0.8045 & 0.15 & 0.333 & 0.118 \\
\hline $1 s^{2} 2 s^{2} 2 p^{2}\left({ }^{3} P\right) n p^{4} P$ & 0.0 & 0.2455 & -0.084 & 0.288 & 0.07 \\
\hline $1 s^{2} 2 s^{2} 2 p^{2}\left({ }^{3} \mathrm{P}\right) n p^{2} \mathrm{P}$ & 0.0 & 0.2455 & -0.084 & 0.248 & 0.05 \\
\hline $1 s^{2} 2 s^{2} 2 p^{2}\left({ }^{3} P\right) n p^{4} D$ & 0.0 & 0.2455 & -0.084 & 0.300 & 0.075 \\
\hline $1 \mathrm{~s}^{2} 2 \mathrm{~s}^{2} 2 \mathrm{p}^{2}\left({ }^{3} \mathrm{P}\right) \mathrm{np}^{2} \mathrm{D}$ & 0.0 & 0.2455 & -0.084 & 0.27 & 0.055 \\
\hline $1 s^{2} 2 s^{2} 2 p^{2}\left({ }^{3} P\right) n p^{4} S$ & 0.0 & 0.2455 & -0.084 & 0.252 & 0.075 \\
\hline $1 s^{2} 2 s^{2} 2 p^{2}\left({ }^{3} P\right) n p^{2} S$ & 0.0 & 0.2455 & -0.084 & 0.322 & 0.081 \\
\hline $1 \mathrm{~s}^{2} 2 \mathrm{~s}^{2} 2 \mathrm{p}^{2}\left({ }^{3} \mathrm{P}\right) n \mathrm{~d}^{4} \mathrm{P}$ & 0.0 & 0.0105 & -0.003 & 0.087 & -0.055 \\
\hline $1 s^{2} 2 s^{2} 2 p^{2}\left({ }^{3} P\right) n d^{2} P$ & 0.0 & 0.0105 & -0.003 & 0.130 & -0.105 \\
\hline $1 s^{2} 2 s^{2} 2 p^{2}\left({ }^{3} P\right) n d^{4} F$ & 0.0 & 0.0105 & -0.003 & 0.130 & -0.075 \\
\hline $1 \mathrm{~s}^{2} 2 \mathrm{~s}^{2} 2 \mathrm{p}^{2}\left({ }^{3} \mathrm{P}\right) \mathrm{nd}^{2} \mathrm{~F}$ & 0.0 & 0.0105 & -0.003 & 0.093 & -0.065 \\
\hline $1 \mathrm{~s}^{2} 2 \mathrm{~s}^{2} 2 \mathrm{p}^{2}\left({ }^{3} \mathrm{P}\right) \mathrm{nd} \mathrm{d}^{4} \mathrm{D}$ & 0.0 & 0.0105 & -0.003 & 0.088 & -0.045 \\
\hline $1 s^{2} 2 s^{2} 2 p^{2}\left({ }^{3} P\right) n d^{2} D$ & 0.0 & 0.0105 & -0.003 & 0.033 & -0.045 \\
\hline $1 s^{2} 2 s 2 p^{3}\left({ }^{5} S\right) 3 s^{4} S$ & 0.0 & 0.8045 & 0.150 & 0.265 & 0.218 \\
\hline $1 s^{2} 2 s 2 p^{3}\left({ }^{5} s\right) 3 s^{6} S$ & 0.0 & 0.8045 & 0.150 & 0.35 & 0.130 \\
\hline
\end{tabular}

\begin{tabular}{|c|c|c|c|c|c|}
\hline $1 \mathrm{~s}^{2} 2 \mathrm{~s} 2 \mathrm{p}^{3}\left({ }^{5} \mathrm{~S}\right) 3 \mathrm{p}^{4} \mathrm{P}$ & 0.0 & 0.2455 & -0.084 & 0.22 & 0.103 \\
\hline $1 \mathrm{~s}^{2} 2 \mathrm{~s} 2 \mathrm{p}^{3}\left({ }^{5} \mathrm{~S}\right) 3 \mathrm{p}^{6} \mathrm{P}$ & 0.0 & 0.2455 & -0.084 & 0.272 & 0.103 \\
\hline $1 \mathrm{~s}^{2} 2 \mathrm{~s} 2 \mathrm{p}^{3}\left({ }^{5} \mathrm{~S}\right) 3 \mathrm{~d}^{4} \mathrm{D}$ & 0.0 & 0.0105 & -0.003 & 0.004 & -0.022 \\
\hline $1 \mathrm{~s}^{2} 2 \mathrm{~s} 2 \mathrm{p}^{3}\left({ }^{5} \mathrm{~S}\right) 3 \mathrm{~d}^{6} \mathrm{D}$ & 0.0 & 0.0105 & -0.003 & 0.096 & -0.035 \\
\hline
\end{tabular}

\section{Energy levels of $1 s^{2} 2 s^{2} 2 p^{2}\left({ }^{3} P\right) n s{ }^{4} P$ states of $\mathrm{N}$-like ions.}

The constants of interaction of $2 \mathrm{~s}$ and $2 \mathrm{p}$ electrons with 1 s electrons are same as in the states of lithium-like ions $1 s^{2} 2 s^{2} \mathrm{~S}$ and $1 \mathrm{~s}^{2} 2 \mathrm{p}^{2} \mathrm{P}$, respectively, or in $1 \mathrm{~s}^{2} 2 \mathrm{~s}^{2} 2 \mathrm{p}^{2}{ }^{3} \mathrm{P}$ states of carbon-like ions. Electrons in ns states interacts with the $1 \mathrm{~s}^{2}$ shell in the same way as in lithium-like ions. For ns states, the parameters of interaction of electrons of the second and third shells were chosen. The calculated values of the energy $1 s^{2} 2 s^{2} 2 p^{2}\left({ }^{3} \mathrm{P}\right) 3 s^{4} \mathrm{P}_{5 / 2}-$ $1 s^{2} 2 s^{2} 2 p^{3}{ }^{4} S_{3 / 2}$ and fine splitting $1 s^{2} 2 s^{2} 2 p^{2} 3 s{ }^{4} P_{5 / 2}-$ $1 s^{2} 2 s^{2} 2 p^{2} 3 s{ }^{4} P_{1 / 2}$ for ions with $\mathrm{Z}=7-20$ are shown in Table. 2. The same table shows a comparison of the calculation with the experimental data the handbooks [12]- [13]. As seen from the comparison, the theoretical and measured values of electronic energies and fine splitting are in good agreement. The fine splitting 1s22s22p23s 4P5/2-1s22s22p23s $4 \mathrm{P} 1 / 2$ is equal to the fine splitting $1 \mathrm{~s}^{2} 2 \mathrm{~s}^{2} 2 \mathrm{p}^{2}{ }^{3} \mathrm{P}_{2}-1 \mathrm{~s}^{2} 2 \mathrm{~s}^{2} 2 \mathrm{p}^{2}{ }^{3} \mathrm{P}_{0}$ calculated taking into account the effect of the third shell electron on the energy levels of the second shell. As the principal quantum number $n$ of the third shell electron increases, $1 s^{2} 2 s^{2} 2 p^{2} n s \quad{ }^{4} \mathrm{P}_{5 / 2} \quad-1 s^{2} 2 s^{2} 2 p^{2} n s \quad{ }^{4} \mathrm{P}_{1 / 2} \quad$ increases, approaching the value $1 \mathrm{~s}^{2} 2 \mathrm{~s}^{2} 2 \mathrm{p}^{2}{ }^{3} \mathrm{P}_{2}-1 \mathrm{~s}^{2} 2 \mathrm{~s}^{2} 2 \mathrm{p}^{2}{ }^{3} \mathrm{P}_{0}$ for carbon-like ions. The comparison of data shows that $1 \mathrm{~s}^{2} 2 \mathrm{~s}^{2} 2 \mathrm{p}^{2} \mathrm{~ns}{ }^{4} \mathrm{P}_{5 / 2}-1 \mathrm{~s}^{2} 2 \mathrm{~s}^{2} 2 \mathrm{p}^{2} \mathrm{~ns}{ }^{4} \mathrm{P}_{1 / 2}$ at $\mathrm{Z}=18$ was probably measured with a large error.

Table 2. Comparison with experiment of the calculated energies (in eV) of $1 s^{2} 2 s^{2} 2 p^{2}\left({ }^{3} \mathrm{P}\right) 3 s^{4} \mathrm{P}_{5 / 2}$ states of N-like ions and fine splitting $1 s^{2} 2 s^{2} 2 p^{2} 3 s^{4} P_{5 / 2}-1 s^{2} 2 s^{2} 2 p^{2} 3 s^{4} P_{1 / 2}$

\begin{tabular}{|c|c|c|c|c|c|c|}
\hline \multirow{2}{*}{$\mathrm{Z}$} & \multicolumn{3}{|c|}{$1 s^{2} 2 s^{2} 2 p^{2}\left({ }^{3} P\right) 3 s^{4} P_{5 / 2}-1 s^{2} 2 s^{2} 2 p^{3}{ }^{4} S_{3 / 2}$} & \multicolumn{3}{|c|}{$1 s^{2} 2 s^{2} 2 p^{2} 3 s^{4} P_{5 / 2}-1 s^{2} 2 s^{2} 2 p^{2} 3 s^{4} P_{1 / 2}$} \\
\hline & $E_{\text {th }}$ & $E_{\exp }$ & $E_{\text {th }}-E_{\text {exp }}$ & $\mathrm{E}_{\text {th }}$ & $E_{\exp }$ & $E_{\text {th }}-E_{\text {exp }}$ \\
\hline 7 & 10.2754 & 10.3362 & -0.06073 & 0.01335 & 0.00998 & 0.00337 \\
\hline 8 & 22.9071 & 22.9992 & -0.09210 & 0.03171 & 0.03271 & -0.00101 \\
\hline 9 & 39.3130 & 39.3328 & -0.01984 & 0.06472 & 0.06549 & -0.00077 \\
\hline 10 & 59.4422 & 59.4696 & -0.02738 & 0.11870 & 0.11779 & 0.00091 \\
\hline 11 & 83.4252 & 83.4119 & 0.01329 & 0.20102 & 0.20098 & 0.00004 \\
\hline 12 & 111.176 & 111.146 & 0.03021 & 0.32021 & 0.30996 & 0.01025 \\
\hline 13 & 142.709 & 142.697 & 0.01227 & 0.48589 & 0.47362 & 0.01226 \\
\hline 14 & 178.048 & 178.058 & -0.01004 & 0.70881 & 0.69556 & 0.01326 \\
\hline 15 & 217.199 & 217.203 & -0.00494 & 1.00091 & 0.97328 & 0.02762 \\
\hline 16 & 260.143 & 260.178 & -0.03502 & 1.37523 & 1.36384 & 0.01139 \\
\hline 17 & 306.913 & 306.955 & -0.04234 & 1.84603 & & \\
\hline 18 & 357.497 & 357.611 & -0.11390 & 2.42873 & 2.14494 & 0.28379 \\
\hline 19 & 411.889 & & & 3.13996 & & \\
\hline 20 & 470.116 & & & 3.99758 & & \\
\hline
\end{tabular}

Comparison with experiment of the calculated energies of $1 s^{2} 2 s^{2} 2 p^{2}\left({ }^{3} P\right) 3 p{ }^{4} D_{7 / 2}, 1 s^{2} 2 s^{2} 2 p^{2}\left({ }^{3} P\right) 3 p{ }^{4} P_{5 / 2}$ states of $\mathrm{N}$-like ions and fine splitting $1 \mathrm{~s}^{2} 2 \mathrm{~s}^{2} 2 \mathrm{p}^{2} 3 \mathrm{p}{ }^{4} \mathrm{D}_{7 / 2}$ ${ }^{-} 1 \mathrm{~s}^{2} 2 \mathrm{~s}^{2} 2 \mathrm{p}^{2} 3 \mathrm{p}{ }^{4} \mathrm{D}_{1 / 2}$ and $1 \mathrm{~s}^{2} 2 \mathrm{~s}^{2} 2 \mathrm{p}^{2} 3 \mathrm{p}{ }^{4} \mathrm{P}_{5 / 2} \quad-$ $1 s^{2} 2 s^{2} 2 p^{2} 3 p^{4} P_{1 / 2}$ values is given in Tables 3 and 4 . The fine splitting $1 s^{2} 2 s^{2} 2 p^{2} 3 p{ }^{4} D_{7 / 2}-1 s^{2} 2 s^{2} 2 p^{2} 3 p{ }^{4} D_{1 / 2}$ is equal to the $1 s^{2} 2 s^{2} 2 p^{2} 3 p{ }^{4} P_{5 / 2}-1 s^{2} 2 s^{2} 2 p^{2} 3 p{ }^{4} P_{1 / 2}$ calculated taking into account the effect of the third shell electron on the state on the second electronic shell. Its slight difference from $1 \mathrm{~s}^{2} 2 \mathrm{~s}^{2} 2 \mathrm{p}^{2} 3 \mathrm{~s} \quad{ }^{4} \mathrm{P}_{5 / 2} \quad-$ $1 s^{2} 2 s^{2} 2 p^{2} 3 s{ }^{4} \mathrm{P}_{1 / 2}$ is explained by the different influence of $3 p$ and $3 s$ electrons on the states of $22 s^{2} 2 p^{2}$ electrons. The fine splitting $1 s^{2} 2 s^{2} 2 p^{2} 3 p{ }^{4} \mathrm{P}_{5 / 2}-1 s^{2} 2 s^{2} 2 p^{2} 3 p{ }^{4} \mathrm{P}_{1 / 2}$ value is equal to half of $1 \mathrm{~s}^{2} 2 \mathrm{~s}^{2} 2 \mathrm{p}^{2}{ }^{3} \mathrm{P}_{2}-1 \mathrm{~s}^{2} 2 \mathrm{~s}^{2} 2 \mathrm{p}^{2}{ }^{3} \mathrm{P}_{0}$ 
calculated with accounting for the effect of the third shell electron on the second shell.

Table 3. Comparison with experiments of the calculated energies (in eV) of $1 s^{2} 2 s^{2} 2 p^{2}\left({ }^{3} P\right) 3 p^{4} D_{7 / 2}$ states of nitrogen-like ions and fine splitting $1 s^{2} 2 s^{2} 2 p^{2} 3 p^{4} D_{7 / 2}-1 s^{2} 2 s^{2} 2 p^{2} 3 p^{4} D_{1 / 2}$

\begin{tabular}{|c|c|c|c|c|c|c|}
\hline \multirow{2}{*}{$\mathrm{Z}$} & \multicolumn{2}{|c|}{$1 \mathrm{~s}^{2} 2 \mathrm{~s}^{2} 2 \mathrm{p}^{2}\left({ }^{3} \mathrm{P}\right) 3 \mathrm{p}^{4} \mathrm{D}_{7 / 2}-1 \mathrm{~s}^{2} 2 \mathrm{~s}^{2} 2 \mathrm{p}^{3}{ }^{4} \mathrm{~S}_{3 / 2}$} & \multicolumn{3}{c|}{$1 \mathrm{~s}^{2} 2 \mathrm{~s}^{2} 2 \mathrm{p}^{2} 3 \mathrm{p}^{4} \mathrm{D}_{7 / 2}-1 \mathrm{~s}^{2} 2 \mathrm{~s}^{2} 2 \mathrm{p}^{2} 3 \mathrm{p}^{4} \mathrm{D}_{1 / 2}$} \\
\hline & $\mathrm{E}_{\mathrm{th}}$ & $\mathrm{E}_{\exp }$ & $\mathrm{E}_{\text {th }}-\mathrm{E}_{\exp }$ & $\mathrm{E}_{\text {th }}$ & $\mathrm{E}_{\exp }$ & $\mathrm{E}_{\text {th }}-\mathrm{E}_{\exp }$ \\
\hline 7 & 11.7395 & 11.7639 & -0.02447 & 0.01374 & 0.01375 & -0.00002 \\
\hline 8 & 25.6715 & 25.6652 & 0.00628 & 0.03270 & 0.03369 & -0.00099 \\
\hline 9 & 43.3078 & 43.3036 & 0.004197 & 0.06657 & 0.06987 & \\
\hline 10 & 64.6054 & & & 0.12165 & & \\
\hline 11 & 89.7067 & & & 0.20534 & & \\
\hline 12 & 118.533 & & & 0.32618 & & \\
\hline 13 & 151.100 & & & 0.49382 & & \\
\hline 14 & 187.432 & & & 0.71906 & & \\
\hline 15 & 227.531 & & & 1.01383 & & \\
\hline 16 & 271.376 & & & 1.39123 & & \\
\hline 17 & 318.993 & & & 2.465217 & & \\
\hline 18 & 370.363 & & & 3.16782 & & \\
\hline 19 & 425.474 & & & 4.03036 & & \\
\hline 20 & 484.344 & & & & & \\
\hline
\end{tabular}

Table 4. Comparison with experiments of the calculated energies (in eV) of $1 \mathrm{~s}^{2} 2 \mathrm{~s}^{2} 2 \mathrm{p}^{2}\left({ }^{3} \mathrm{P}\right) 3 \mathrm{p}^{4} \mathrm{P}_{5 / 2}$ states of nitrogen-like ions and fine splitting $1 s^{2} 2 s^{2} 2 p^{2} 3 p^{4} \mathrm{P}_{5 / 2}-1 s^{2} 2 s^{2} 2 p^{2} 3 p^{4} \mathrm{P}_{1 / 2}$

\begin{tabular}{|c|c|c|c|c|c|c|}
\hline \multirow{2}{*}{$\mathrm{Z}$} & \multicolumn{3}{|c|}{$1 s^{2} 2 s^{2} 2 p^{2}\left({ }^{3} P\right) 3 p{ }^{4} P_{5 / 2}-1 s^{2} 2 s^{2} 2 p^{34} S_{3 / 2}$} & \multicolumn{3}{|c|}{$1 s^{2} 2 s^{2} 2 p^{2} 3 p^{4} P_{5 / 2}-1 s^{2} 2 s^{2} 2 p^{2} 3 p^{4} P_{1 / 2}$} \\
\hline & $\mathrm{E}_{\text {th }}$ & $E_{\text {exp }}$ & $E_{\text {th }}-E_{\text {exp }}$ & $\mathrm{E}_{\mathrm{th}}$ & $E_{\text {exp }}$ & $E_{\text {th }}-E_{\text {exp }}$ \\
\hline 7 & 11.8377 & 11.8447 & -0.00697 & 0.00689 & 0.00703 & -0.00014 \\
\hline 8 & 25.8834 & 25.8490 & 0.03446 & 0.01641 & 0.01712 & -0.00071 \\
\hline 9 & 43.6356 & 43.5829 & 0.05272 & 0.03340 & 0.03509 & -0.00168 \\
\hline 10 & 65.0483 & 65.0943 & -0.04608 & 0.06102 & 0.07761 & -0.01659 \\
\hline 11 & 90.2631 & & & 0.10298 & & \\
\hline 12 & 119.201 & & & 0.16353 & & \\
\hline 13 & 151.880 & & & 0.24753 & & \\
\hline 14 & 188.321 & & & 0.36035 & & \\
\hline 15 & 228.531 & & & 0.50798 & & \\
\hline 16 & 272.485 & & & 0.69696 & & \\
\hline 17 & 320.210 & & & 0.93444 & & \\
\hline 18 & 371.688 & & & 1.22814 & & \\
\hline 19 & 426.908 & & & 1.58640 & & \\
\hline 20 & 485.886 & & & 2.01816 & & \\
\hline
\end{tabular}

Comparison of the calculated energies of $1 s^{2} 2 s^{2} 2 p^{2}\left({ }^{3} \mathrm{P}\right) 3 p^{2} S_{1 / 2}$ and $1 s^{2} 2 s^{2} 2 p^{2}\left({ }^{3} \mathrm{P}\right) 3 p^{4} S_{3 / 2}$ states of nitrogen-like ions with experiment data is shown in Table 5. Experimental data [12]-[13] are available for ions with $\mathrm{Z}=7-9$ only. As seen from the comparison, the relative deviation of the theory from measurements is in the order of $10^{-4}-10^{-3}$.

Table 5. Comparison with experiments of the calculated energies (in eV) of $1 s^{2} 2 s^{2} 2 p^{2}\left({ }^{3} \mathrm{P}\right) 3 \mathrm{p}^{4} \mathrm{P}_{5 / 2}$ states of nitrogen-like ions and fine splitting $1 s^{2} 2 s^{2} 2 p^{2} 3 p^{4} P_{5 / 2}-1 s^{2} 2 s^{2} 2 p^{2} 3 p^{4} P_{1 / 2}$

\begin{tabular}{|c|c|c|c|c|c|c|}
\hline \multirow{2}{*}{$\mathrm{Z}$} & \multicolumn{2}{|c|}{$1 \mathrm{~s}^{2} 2 \mathrm{~s}^{2} 2 \mathrm{p}^{2} 3 \mathrm{p}^{2} \mathrm{~S}_{1 / 2}-1 \mathrm{~s}^{2} 2 \mathrm{~s}^{2} 2 \mathrm{p}^{3} \mathrm{~S}_{3 / 2}$} & \multicolumn{3}{c|}{$1 \mathrm{~s}^{2} 2 \mathrm{~s}^{2} 2 \mathrm{p}^{2} 3 \mathrm{p}^{4} \mathrm{~S}_{3 / 2}-1 \mathrm{~s}^{2} 2 \mathrm{~s}^{2} 2 \mathrm{p}^{3} \mathrm{~S}_{3 / 2}$} \\
\hline & $\mathrm{E}_{\text {th }}$ & $\mathrm{E}_{\exp }$ & $\mathrm{E}_{\text {th }}-\mathrm{E}_{\exp }$ & $\mathrm{E}_{\text {th }}$ & $\mathrm{E}_{\text {exp }}$ & $\mathrm{E}_{\exp }$ \\
\hline 7 & 11.5665 & 11.6027 & -0.03619 & 11.9957 & 11.9958 & -0.00011 \\
\hline 8 & 25.2895 & 25.2858 & 0.00371 & 26.3050 & 26.3049 & 0.00001 \\
\hline 9 & 42.7118 & 42.7053 & 0.00658 & 44.3600 & 44.3219 & 0.03817 \\
\hline 10 & 63.7976 & & & 66.0871 & 66.0814 & 0.00572 \\
\hline 11 & 88.6902 & & & 91.6207 & & \\
\hline 12 & 117.310 & & & 120.879 & & \\
\hline 13 & 149.674 & & & 153.879 & & \\
\hline 14 & 185.803 & & & 231.171 & & \\
\hline 15 & 225.701 & & & 275.446 & & \\
\hline 16 & 269.346 & & & 323.491 & & \\
\hline 17 & 316.763 & & & 375.290 & & \\
\hline 18 & 367.934 & & & 430.830 & & \\
\hline 19 & 422.847 & & & 490.129 & & \\
\hline 20 & 481.519 & & & & & \\
\end{tabular}


Comparison of the calculated energies of $1 s^{2} 2 s^{2} 2 p^{2}\left({ }^{3} P\right) 3 p^{2} D_{5 / 2}$ states of nitrogen-like ions and fine splitting $1 s^{2} 2 s^{2} 2 p^{2} 3 p{ }^{2} D_{5 / 2}-1 s^{2} 2 s^{2} 2 p^{2} 3 p{ }^{2} D_{3 / 2}$ with experimental data is given in Table 6. Fine splitting
$1 s^{2} 2 s^{2} 2 p^{2} 3 p^{2} D_{5 / 2}-1 s^{2} 2 s^{2} 2 p^{2} 3 p^{2} D_{3 / 2}$ is equal to $2 / 3$ of $1 s^{2} 2 s^{2} 2 p^{2}{ }^{3} \mathrm{P}_{2}-1 s^{2} 2 s^{2} 2 p^{2}{ }^{3} \mathrm{P}_{0}$ calculated taking into account the effect of the third shell electron on the electrons of the second shell.

Table 6. Comparison with experiments of the calculated energies (in eV) of $1 s^{2} 2 s^{2} 2 p^{2}\left({ }^{3} P\right) 3 p^{2} D_{5 / 2}$ states of nitrogen-like ions and fine splitting $1 s^{2} 2 s^{2} 2 p^{2} 3 p^{2} D_{5 / 2}-1 s^{2} 2 s^{2} 2 p^{2} 3 p^{2} D_{3 / 2}$

\begin{tabular}{|c|c|c|c|c|c|c|}
\hline \multirow{2}{*}{ Z } & \multicolumn{3}{|c|}{$1 s^{2} 2 s^{2} 2 p^{2}\left({ }^{3} P\right) 3 p^{2} D_{5 / 2}-1 s^{2} 2 s^{2} 2 p^{3}{ }^{4} S_{3 / 2}$} & \multicolumn{3}{|c|}{$1 s^{2} 2 s^{2} 2 p^{2} 3 p^{2} D_{5 / 2}-1 s^{2} 2 s^{2} 2 p^{2} 3 p^{2} D_{3 / 2}$} \\
\hline & $\mathrm{E}_{\mathrm{th}}$ & $E_{\exp }$ & $E_{\text {th }}-E_{\text {exp }}$ & $\mathrm{E}_{\mathrm{th}}$ & $E_{\text {exp }}$ & $E_{\text {th }}-E_{\text {exp }}$ \\
\hline 7 & 12.0203 & 12.0097 & 0.01063 & 0.00920 & 0.00947 & -0.00026 \\
\hline 8 & 26.2501 & 26.2492 & 0.00088 & 0.02194 & 0.01124 & 0.01070 \\
\hline 9 & 44.1840 & 44.1846 & -0.00063 & 0.04467 & 0.04840 & -0.00373 \\
\hline 10 & 65.7740 & & & 0.08159 & & \\
\hline 11 & 91.1626 & & & 0.13767 & & \\
\hline 12 & 120.271 & & & 0.21858 & & \\
\hline 13 & 153.119 & & & 0.33078 & & \\
\hline 14 & 189.727 & & & 0.48147 & & \\
\hline 15 & 230.102 & & & 0.67862 & & \\
\hline 16 & 274.221 & & & 0.93096 & & \\
\hline 17 & 322.110 & & & 1.24802 & & \\
\hline 18 & 373.752 & & & 1.64011 & & \\
\hline 19 & 429.134 & & & 2.11834 & & \\
\hline 20 & 488.275 & & & 2.69464 & & \\
\hline
\end{tabular}

A comparison of the calculated energies of $1 s^{2} 2 s^{2} 2 p^{2}\left({ }^{3} \mathrm{P}\right) 3 p^{2} \mathrm{P}_{3 / 2}$ states of nitrogen-like ions and fine splitting $1 \mathrm{~s}^{2} 2 \mathrm{~s}^{2} 2 \mathrm{p}^{2} 3 \mathrm{p}{ }^{2} \mathrm{P}_{3 / 2}-1 \mathrm{~s}^{2} 2 \mathrm{~s}^{2} 2 \mathrm{p}^{2} 3 \mathrm{p}{ }^{2} \mathrm{P}_{1 / 2}$ with measurements is given in Table 7 . The fine splitting
$1 s^{2} 2 s^{2} 2 p^{2} 3 p \quad{ }^{2} \mathrm{P}_{3 / 2}-1 s^{2} 2 s^{2} 2 p^{2} 3 p \quad{ }^{2} \mathrm{P}_{1 / 2} \quad$ is $1 / 3$ of $1 \mathrm{~s}^{2} 2 \mathrm{~s}^{2} 2 \mathrm{p}^{2}{ }^{3} \mathrm{P}_{2}-1 \mathrm{~s}^{2} 2 \mathrm{~s}^{2} 2 \mathrm{p}^{2}{ }^{3} \mathrm{P}_{0}$ calculated taking into account the effect of the third shell electron on the electrons of the second shell.

Table 7. Comparison of the calculated energies (in eV) of $1 \mathrm{~s}^{2} 2 \mathrm{~s}^{2} 2 \mathrm{p}^{2}\left({ }^{3} \mathrm{P}\right) 3 \mathrm{p}^{2} \mathrm{P}_{3 / 2}$ states of nitrogen-like ions and fine splitting $1 s^{2} 2 s^{2} 2 p^{2} 3 p^{2} P_{3 / 2}-1 s^{2} 2 s^{2} 2 p^{2} 3 p^{2} P_{1 / 2}$ with experiments.

\begin{tabular}{|c|c|c|c|c|c|c|}
\hline \multirow{2}{*}{$\mathrm{Z}$} & \multicolumn{3}{|c|}{$1 s^{2} 2 s^{2} 2 p^{2}\left({ }^{3} P\right) 3 p^{2} P_{3 / 2}-1 s^{2} 2 s^{2} 2 p^{34} S_{3 / 2}$} & \multicolumn{3}{|c|}{$1 s^{2} 2 s^{2} 2 p^{2} 3 p^{2} \mathrm{P}_{3 / 2}-1 s^{2} 2 s^{2} 2 p^{2} 3 p^{2} \mathrm{P}_{1 / 2}$} \\
\hline & $\mathrm{E}_{\text {th }}$ & $\mathrm{E}_{\exp }$ & $E_{\text {th }}-E_{\text {exp }}$ & $\mathrm{E}_{\mathrm{th}}$ & $E_{\exp }$ & $E_{\text {th }}-E_{\text {exp }}$ \\
\hline 7 & 12.1506 & 12.1265 & 0.02418 & 0.00461 & 0.00443 & 0.00019 \\
\hline 8 & 26.5607 & 26.5613 & -0.00057 & 0.01101 & 0.00741 & 0.00360 \\
\hline 9 & 44.6888 & 44.6884 & 0.00040 & 0.02241 & 0.01077 & 0.01164 \\
\hline 10 & 66.4770 & & & 0.04094 & & \\
\hline 11 & 92.0647 & & & 0.06906 & & \\
\hline 12 & 121.372 & & & 0.10964 & & \\
\hline 13 & 154.419 & & & 0.16588 & & \\
\hline 14 & 191.225 & & & 0.24140 & & \\
\hline 15 & 231.798 & & & 0.34019 & & \\
\hline 16 & 276.114 & & & 0.46661 & & \\
\hline 17 & 324.200 & & & 0.62543 & & \\
\hline 18 & 376.038 & & & 0.82181 & & \\
\hline 19 & 431.618 & & & 1.06132 & & \\
\hline 20 & 490.955 & & & 1.34991 & & \\
\hline
\end{tabular}

The energies of $1 \mathrm{~s}^{2} 2 \mathrm{~s}^{2} 2 \mathrm{p}^{2}\left({ }^{3} \mathrm{P}\right) 3 \mathrm{~d} \quad{ }^{4,2} \mathrm{~F}$, $1 s^{2} 2 s^{2} 2 p^{2}\left({ }^{3} P\right) 3 d{ }^{4,2} \mathrm{D}, \quad 1 s^{2} 2 s^{2} 2 p^{2}\left({ }^{3} P\right) 3 d \quad{ }^{4} \mathrm{P}$ states of nitrogen-like ions were calculated. The constants of interaction of $2 \mathrm{~s}$ and $2 \mathrm{p}$ electrons with 1 s electrons were the same as in the case of the states of lithium-like ions $1 s^{2} 2 s^{2} S$ and $1 s^{2} 2 p^{2} P$, respectively or $1 s^{2} 2 s^{2} 2 p^{2}{ }^{3} P$ states of carbon-like ions. The electron in nd states interacts with the $1 \mathrm{~s}^{2}$ shell in the same way as in lithium-like ions. For nd states, the parameters of interaction of electrons of the second and third shells were chosen. The calculated values of the energy 1s22s22p2 (3P) 3d 4F9 / $2-11 \mathrm{~s}^{2} 2 \mathrm{~s}^{2} 2 \mathrm{p}^{2}{ }^{3} \mathrm{P}$ s22s22p3 4S3 / 2 and fine splitting 1s22s22p23d 4F9 / 2-1s22s22p23d 4F3 / 2 for ions with
$\mathrm{Z}=7-20$ are given in Table. 8 . The same table shows a comparison of the calculated values with experimental data taken from the handbooks [12], [13]. The calculated values are in good agreement with the experiment. The fine splitting $1 s^{2} 2 s^{2} 2 p^{2} 3 d^{4} F_{9 / 2}-1 s^{2} 2 s^{2} 2 p^{2} 3 d^{4} F_{3 / 2}$ is equal to the fine splitting $1 s^{2} 2 s^{2} 2 p^{2} \quad{ }^{3} \mathrm{P}_{2}-1 s^{2} 2 s^{2} 2 p^{2}{ }^{3} \mathrm{P}_{0}$ calculated with accounting for the impact of the third shell electron on the second shell electrons. Its slight difference from $1 s^{2} 2 s^{2} 2 p^{2} 3 s{ }^{4} P_{5 / 2}-1 s^{2} 2 s^{2} 2 p^{2} 3 s{ }^{4} P_{1 / 2}$ is explained by the different influence of $3 d$ and $3 s$ electrons on the state of $2 s^{2} 2 p^{2}$ electrons. 
Table 8. Comparison of the calculated energies (in eV) of $1 \mathrm{~s}^{2} 2 \mathrm{~s}^{2} 2 \mathrm{p}^{2}\left({ }^{3} \mathrm{P}\right) 3 \mathrm{~d}{ }^{4} \mathrm{~F}_{9 / 2}$ states of nitrogen-like ions and fine splitting $1 s^{2} 2 s^{2} 2 p^{2} 3 d^{4} F_{9 / 2}-1 s^{2} 2 s^{2} 2 p^{2} 3 d F_{3 / 2}$ with experiments.

\begin{tabular}{|c|c|c|c|c|c|c|}
\hline \multirow{2}{*}{$\mathrm{Z}$} & \multicolumn{2}{|c|}{$1 \mathrm{~s}^{2} 2 \mathrm{~s}^{2} 2 \mathrm{p}^{2}\left({ }^{3} \mathrm{P}\right) 3 \mathrm{~d}^{4} \mathrm{~F}_{9 / 2}-1 \mathrm{~s}^{2} 2 \mathrm{~s}^{2} 2 \mathrm{p}^{3}{ }^{4} \mathrm{~S}_{3 / 2}$} & \multicolumn{3}{c|}{$1 \mathrm{~s}^{2} 2 \mathrm{~s}^{2} 2 \mathrm{p}^{2} 3 \mathrm{~d}^{4} \mathrm{~F}_{9 / 2}-1 \mathrm{~s}^{2} 2 \mathrm{~s}^{2} 2 \mathrm{p}^{2} 3 \mathrm{~d}^{4} \mathrm{~F}_{3 / 2}$} \\
\hline & $\mathrm{E}_{\text {th }}$ & $\mathrm{E}_{\exp }$ & $\mathrm{E}_{\text {th }}-\mathrm{E}_{\exp }$ & $\mathrm{E}_{\text {th }}$ & $\mathrm{E}_{\exp }$ & $\mathrm{E}_{\text {th }}-\mathrm{E}_{\exp }$ \\
\hline 7 & 13.1289 & 12.9896 & 0.13938 & 0.01401 & 0.01265 & 0.00136 \\
\hline 8 & 28.7120 & 28.6939 & 0.01808 & 0.03357 & 0.01664 & 0.01693 \\
\hline 9 & 48.0746 & 48.0722 & 0.00240 & 0.06844 & 0.05805 & 0.01039 \\
\hline 10 & 71.1253 & & & 0.12498 & & \\
\hline 11 & 97.9919 & & & 0.21067 & & \\
\hline 12 & 128.591 & & & 0.33412 & & \\
\hline 13 & 162.941 & & & 0.50505 & & \\
\hline 14 & 201.064 & & & 0.73432 & & \\
\hline 15 & 242.968 & & & 1.03395 & & \\
\hline 16 & 288.635 & & & 1.41711 & & \\
\hline 17 & 338.093 & & & 1.89813 & & \\
\hline 18 & 391.329 & & & 2.49255 & & \\
\hline 19 & 448.335 & & & 3.21711 & & \\
\hline 20 & 509.133 & & & 4.08975 & & \\
\hline
\end{tabular}

Comparison with experiments of the calculated energies of $1 s^{2} 2 s^{2} 2 p^{2}\left({ }^{3} P\right) 3 d{ }^{4} D_{7 / 2}-1 s^{2} 2 s^{2} 2 p^{3}{ }^{4} S_{3 / 2}$, $1 s^{2} 2 s^{2} 2 p^{2}\left({ }^{3} \mathrm{P}\right) 3 d^{4} \mathrm{P}_{5 / 2}-1 s^{2} 2 s^{2} 2 p^{3}{ }^{4} S_{3 / 2}$ states of nitrogenlike ions and fine splitting $1 \mathrm{~s}^{2} 2 \mathrm{~s}^{2} 2 \mathrm{p}^{2} 3 \mathrm{~d}{ }^{4} \mathrm{D}_{7 / 2}-$ $1 \mathrm{~s}^{2} 2 \mathrm{~s}^{2} 2 \mathrm{p}^{2} 3 \mathrm{~d} \quad{ }^{4} \mathrm{D}_{1 / 2}$ and $1 \mathrm{~s}^{2} 2 \mathrm{~s}^{2} 2 \mathrm{p}^{2} 3 \mathrm{~d} \quad{ }^{4} \mathrm{P}_{5 / 2} \quad$ $1 s^{2} 2 s^{2} 2 p^{2} 3 d^{4} P_{1 / 2}$ is given in Tables 9 and 10. The fine splitting interval $1 s^{2} 2 s^{2} 2 p^{2} 3 d{ }^{4} D_{7 / 2}-1 s^{2} 2 s^{2} 2 p^{2} 3 d{ }^{4} D_{1 / 2}$ is 0.33 of the fine splitting calculated with accounting for the impact of the third shell electron on the second shell electrons. The fine splitting $1 \mathrm{~s}^{2} 2 \mathrm{~s}^{2} 2 \mathrm{p}^{2} 3 \mathrm{~d}{ }^{4} \mathrm{P}_{5 / 2} \quad$ $1 s^{2} 2 s^{2} 2 p^{2} 3 d{ }^{4} P_{1 / 2}$ is equal to half of the fine splitting $1 \mathrm{~s}^{2} 2 \mathrm{~s}^{2} 2 \mathrm{p}^{2}{ }^{3} \mathrm{P}_{2}-1 \mathrm{~s}^{2} 2 \mathrm{~s}^{2} 2 \mathrm{p}^{2}{ }^{3} \mathrm{P}_{0}$.

Table 9. Comparison of the calculated energies (in eV) of $1 s^{2} 2 s^{2} 2 p^{2}\left({ }^{3} P\right) 3 d^{4} D_{7 / 2}-1 s^{2} 2 s^{2} 2 p^{3} S_{3 / 2}$ and $1 s^{2} 2 s^{2} 2 p^{3}{ }^{4} S_{3 / 2}$ states of nitrogen-like ions and fine splitting $1 s^{2} 2 s^{2} 2 p^{2} 3 d^{4} D_{7 / 2}-1 s^{2} 2 s^{2} 2 p^{2} 3 d^{4} D_{1 / 2}$ with experiments.

\begin{tabular}{|c|c|c|c|c|c|c|}
\hline \multirow{2}{*}{$\mathrm{Z}$} & \multicolumn{3}{|c|}{$1 s^{2} 2 s^{2} 2 p^{2}\left({ }^{3} P\right) 3 d^{4} D_{7 / 2}-1 s^{2} 2 s^{2} 2 p^{3}{ }^{4} s_{3 / 2}$} & \multicolumn{3}{|c|}{$1 s^{2} 2 s^{2} 2 p^{2} 3 d^{4} D_{7 / 2}-1 s^{2} 2 s^{2} 2 p^{2} 3 d^{4} D_{1 / 2}$} \\
\hline & $\mathrm{E}_{\text {th }}$ & $E_{\exp }$ & $E_{\text {th }}-E_{\text {exp }}$ & $\mathrm{E}_{\text {th }}$ & $E_{\exp }$ & $E_{\text {th }}-E_{\text {exp }}$ \\
\hline 7 & 13.1004 & 13.0209 & 0.07945 & 0.00467 & 0.00409 & 0.00058 \\
\hline 8 & 28.8158 & 28.8580 & -0.04222 & 0.01120 & 0.00523 & 0.00597 \\
\hline 9 & 48.3931 & 48.3801 & 0.01301 & 0.02285 & 0.01116 & 0.01169 \\
\hline 10 & 71.7037 & & & 0.04175 & & \\
\hline 11 & 98.8576 & & & 0.07040 & & \\
\hline 12 & 129.762 & & & 0.11167 & & \\
\hline 13 & 164.429 & & & 0.16880 & & \\
\hline 14 & 202.878 & & & 0.24544 & & \\
\hline 15 & 245.115 & & & 0.34558 & & \\
\hline 16 & 291.119 & & & 0.47362 & & \\
\hline 17 & 340.917 & & & 0.63436 & & \\
\hline 18 & 394.496 & & & 0.83296 & & \\
\hline 19 & 451.847 & & & 1.07502 & & \\
\hline 20 & 512.992 & & & 1.36653 & & \\
\hline
\end{tabular}

\section{Conclusion}

Electronic energies of one-electron excited states $1 \mathrm{~s}^{2} 2 \mathrm{~s}^{2} 2 \mathrm{p}^{2} \mathrm{~ns} \quad{ }^{4} \mathrm{P}, \quad 1 \mathrm{~s}^{2} 2 \mathrm{~s}^{2} 2 \mathrm{p}^{2} \mathrm{~ns} \quad{ }^{2} \mathrm{P}, \quad 1 \mathrm{~s}^{2} 2 \mathrm{~s}^{2} 2 \mathrm{p}^{2} \mathrm{np} \quad{ }^{4} \mathrm{~S}$, $1 \mathrm{~s}^{2} 2 \mathrm{~s}^{2} 2 \mathrm{p}^{2} \mathrm{np} \quad{ }^{2} \mathrm{~S}, \quad 1 \mathrm{~s}^{2} 2 \mathrm{~s}^{2} 2 \mathrm{p}^{2} \mathrm{np} \quad{ }^{4} \mathrm{P}, \quad 1 \mathrm{~s}^{2} 2 \mathrm{~s}^{2} 2 \mathrm{p}^{2} \mathrm{np} \quad{ }^{2} \mathrm{P}$, $1 \mathrm{~s}^{2} 2 \mathrm{~s}^{2} 2 \mathrm{p}^{2} \mathrm{np} \quad{ }^{4} \mathrm{D}, \quad 1 \mathrm{~s}^{2} 2 \mathrm{~s}^{2} 2 \mathrm{p}^{2} \mathrm{np} \quad{ }^{2} \mathrm{D}, \quad 1 \mathrm{~s}^{2} 2 \mathrm{~s}^{2} 2 \mathrm{p}^{2} \mathrm{nd} \quad{ }^{4} \mathrm{P}$, $1 s^{2} 2 s^{2} 2 p^{2}$ nd $\quad{ }^{2} \mathrm{P}, \quad 1 s^{2} 2 s^{2} 2 p^{2}$ nd $\quad{ }^{4} \mathrm{D}, \quad 1 s^{2} 2 s^{2} 2 p^{2}$ nd $\quad{ }^{2} \mathrm{D}$, $1 s^{2} 2 s^{2} 2 p^{2} n d{ }^{4} F, 1 s^{2} 2 s^{2} 2 p^{2}$ nd ${ }^{2} F$ of nitrogen-like ions with $n=3-12$ and $Z=7-50$ have been calculated. For all the aforementioned electronic configurations, fine-structure levels have been determined for states with different total momentum J. The comparison of theoretical results with the available experimental data shows that theory and measurements agree well. In particular, relative accuracy of $10^{-4}$ has been achieved in the electronic energy of $\mathrm{N}$-like at $\mathrm{Z}>10$, while the typical deviation in the calculated fine-structure levels from experimental data is in the order of $10^{-2}$.

The dependences of the fine structure on the nuclear charge $\mathrm{Z}$ and the principal quantum number $n$ for a number of configurations of nitrogen-like ions have been determined. The fine splitting $1 s^{2} 2 s^{2} 2 p^{2} 3 s{ }^{4} \mathrm{P}_{5 / 2} \quad-$ $1 s^{2} 2 s^{2} 2 p^{2} 3 s{ }^{4} \mathrm{P}_{1 / 2}$ of the energy levels of N-like ions is equal to the fine splitting of $1 \mathrm{~s}^{2} 2 \mathrm{~s}^{2} 2 \mathrm{p}^{2}{ }^{3} \mathrm{P}_{2}-1 \mathrm{~s}^{2} 2 \mathrm{~s}^{2} 2 \mathrm{p}^{2} \mathrm{P}_{0}$ of the energy levels of carbon- like ions calculated taking into account the influence of the third shell electron on the state of the second shell electrons. With the increase in the principal quantum number $n$ of the third shell electron, the fine splitting $1 s^{2} 2 s^{2} 2 p^{2} n s{ }^{4} \mathrm{P}_{5 / 2}-$ $1 s^{2} 2 s^{2} 2 p^{2} n s{ }^{4} P_{1 / 2}$ slightly increases, reaching the value of the fine splitting $1 s^{2} 2 s^{2} 2 p^{2}{ }^{3} P_{2}-1 s^{2} 2 s^{2} 2 p^{2}{ }^{3} P_{0}$ for carbon-like ions. The fine splitting $1 s^{2} 2 s^{2} 2 p^{2} 3 p{ }^{4} P_{5 / 2}-$

e-mail: anadykto@gmail.com 
$1 s^{2} 2 s^{2} 2 p^{2} 3 p{ }^{4} \mathrm{P}_{1 / 2}$ is equal to 0.5 of the fine splitting $1 s^{2} 2 s^{2} 2 p^{2}{ }^{3} \mathrm{P}_{2}-1 s^{2} 2 s^{2} 2 p^{2}{ }^{3} \mathrm{P}_{0}$. The fine splitting $1 s^{2} 2 s^{2} 2 p^{2} 3 p^{2} \mathrm{P}_{3 / 2}-1 s^{2} 2 s^{2} 2 p^{2} 3 p^{2} \mathrm{P}_{1 / 2}$ is equal to the fine splitting $1 \mathrm{~s}^{2} 2 \mathrm{~s}^{2} 2 \mathrm{p}^{2}{ }^{3} \mathrm{P}_{2}-1 \mathrm{~s}^{2} 2 \mathrm{~s}^{2} 2 \mathrm{p}^{2}{ }^{3} \mathrm{P}_{0}$. The fine splitting $1 s^{2} 2 s^{2} 2 p^{2} 3 p^{2} D_{5 / 2}-1 s^{2} 2 s^{2} 2 p^{2} 3 p{ }^{2} D_{3 / 2}$ is equal to $2 / 3$ of $1 s^{2} 2 s^{2} 2 p^{2}{ }^{3} \mathrm{P}_{2}-1 s^{2} 2 s^{2} 2 \mathrm{p}^{2}{ }^{3} \mathrm{P}_{0}$. The fine splitting $1 s^{2} 2 s^{2} 2 p^{2} 3 p^{2} \mathrm{P}_{3 / 2}-1 s^{2} 2 s^{2} 2 p^{2} 3 p^{2} \mathrm{P}_{1 / 2}$ is equal to 0.33 of the fine splitting $1 \mathrm{~s}^{2} 2 \mathrm{~s}^{2} 2 \mathrm{p}^{2}{ }^{3} \mathrm{P}_{2}-1 \mathrm{~s}^{2} 2 \mathrm{~s}^{2} 2 \mathrm{p}^{2}{ }^{3} \mathrm{P}_{0}$. The fine splitting $1 s^{2} 2 s^{2} 2 p^{2} 3 d{ }^{4} F_{9 / 2}-1 s^{2} 2 s^{2} 2 p^{2} 3 d^{4} F_{3 / 2}$ is equal to the fine splitting $1 s^{2} 2 s^{2} 2 p^{2}{ }^{3} \mathrm{P}_{2}-1 \mathrm{~s}^{2} 2 \mathrm{~s}^{2} 2 \mathrm{p}^{2}{ }^{3} \mathrm{P}_{0}$. Its slight difference from the $1 s^{2} 2 s^{2} 2 p^{2} 3 s^{4} \mathrm{P}_{5 / 2}-1 s^{2} 2 s^{2} 2 p^{2} 3 s^{4} \mathrm{P}_{1 / 2}$ is explained by the different influence of $3 \mathrm{~d}$ and $3 \mathrm{~s}$ electrons on the state of $2 s^{2} 2 p^{2}$ electrons. The fine splitting $1 s^{2} 2 s^{2} 2 p^{2} 3 d{ }^{4} D_{7 / 2}-1 s^{2} 2 s^{2} 2 p^{2} 3 d^{4} D_{1 / 2}$ is equal to 0.33 of the fine splitting $1 \mathrm{~s}^{2} 2 \mathrm{~s}^{2} 2 \mathrm{p}^{2}{ }^{3} \mathrm{P}_{2}-1 \mathrm{~s}^{2} 2 \mathrm{~s}^{2} 2 \mathrm{p}^{2}{ }^{3} \mathrm{P}_{0}$. The fine splitting $1 s^{2} 2 s^{2} 2 p^{2} 3 d^{4} P_{5 / 2}-1 s^{2} 2 s^{2} 2 p^{2} 3 d^{4} P_{1 / 2}$ is equal to 0.5 of the fine splitting $1 \mathrm{~s}^{2} 2 \mathrm{~s}^{2} 2 \mathrm{p}^{2}{ }^{3} \mathrm{P}_{2}-$ $1 \mathrm{~s}^{2} 2 \mathrm{~s}^{2} 2 \mathrm{p}^{2}{ }^{3} \mathrm{P}_{0}$. The fine splitting $1 \mathrm{~s}^{2} 2 \mathrm{~s}^{2} 2 \mathrm{p}^{2} 3 \mathrm{~d}{ }^{2} \mathrm{D}_{5 / 2}-$ $1 \mathrm{~s}^{2} 2 \mathrm{~s}^{2} 2 \mathrm{p}^{2} 3 \mathrm{~d}^{2} \mathrm{D}_{3 / 2}$ is equal to 0.2 of the fine splitting $1 s^{2} 2 s^{2} 2 p^{2}{ }^{3} \mathrm{P}_{2}-1 s^{2} 2 s^{2} 2 p^{2}{ }^{3} \mathrm{P}_{0}$. In the case of the fine splitting of $1 \mathrm{~s}^{2} 2 \mathrm{~s}^{2} 2 \mathrm{p}^{2} 3 \mathrm{~d}^{2} \mathrm{P}$, the energy $1 \mathrm{~s}^{2} 2 \mathrm{~s}^{2} 2 \mathrm{p}^{2} 3 \mathrm{~d}^{2} \mathrm{P}_{3 / 2}$ is lower than that of $1 \mathrm{~s}^{2} 2 \mathrm{~s}^{2} 2 \mathrm{p}^{2} 3 \mathrm{~d}^{2} \mathrm{P}_{1 / 2}$ and fine splitting $1 s^{2} 2 s^{2} 2 p^{2} 3 d^{2} P_{1 / 2}-1 s^{2} 2 s^{2} 2 p^{2} 3 d{ }^{2} P_{3 / 2}$ is equal to 0.33 of $1 s^{2} 2 s^{2} 2 p^{2} \mathrm{P}_{3 / 2}-1 s^{2} 2 s^{2} 2 p^{2} \mathrm{P}_{1 / 2}$.

Experimental data for the energy levels of outer electrons in $\mathrm{N}$-like ions with the principal quantum number $n>3$ are very limited. However, taken together, they confirm the correctness of the proposed theoretical approach, which was validated in more detail at $n=3$. In many cases, the fine splitting of $\mathrm{N}$-like ions is associated with the splitting of the energy of the $1 s^{2} 2 s^{2} 2 p^{2}$ state of carbon-like ions and does not decrease with increasing $n$. Instead, it slightly increases, approaching the value of the fine splitting $1 \mathrm{~s}^{2} 2 \mathrm{~s}^{2} 2 \mathrm{p}^{2}{ }^{3} \mathrm{P}_{2}-1 \mathrm{~s}^{2} 2 \mathrm{~s}^{2} 2 \mathrm{p}^{2}{ }^{3} \mathrm{P}_{0}$ for carbonlike ions. The fine splitting of the energy levels of $n l$ electrons is small compared to the interval $1 \mathrm{~s}^{2} 2 \mathrm{~s}^{2} 2 \mathrm{p}^{2}{ }^{3} \mathrm{P}_{2}$ $-1 s^{2} 2 s^{2} 2 p^{2}{ }^{3} P_{0}$ and decreases sharply with increasing $n$.

\section{Acknowledgments}

This work was partially supported by the RSF project No. 18-11-00247. This work was carried out using equipment provided by the Center of Collective Use of MSUT "STANKIN".

\section{References}

1. L.D. Landau, E.M. Lifshitz, Quantum mechanics: non-relativistic theory (Vol. 3) (Pergamon Press Ltd. 1977)

ISBN:0-08-020940-8

2. H.A. Bethe, E.E. Salpeter, Quantum mechanics of one-and two-electron atoms (Springer Science \& Business Media, 2012) ISBN-13: 978-0-306-20022-9

3. P.A.M. Dirac, The principles of quantum mechanics (No. 27) (Oxford University Press, 1981) ISBN: 0-19-852011-5
4. E.U. Condon, E.U. Condon, G.H. Shortley, The theory of atomic spectra. (Cambridge University Press., 1951)

ISBN: 0-521-09209-4

5. I.I. Sobelman. Introduction to the theory of atomic spectra (Moscow: Nauka, 1977) [in Russian]

6. C. Froese-Fischer, The Hartree-Fock method for atoms: a numerical approach (Wiley, 1977)

7. R.D. Cowan, The theory of atomic structure and spectra (No. 3) (Univ of California Press., 1981) ISBN: 978-0-520-03821-9

8. A.A. Nikitin, Z.B. Rudzikas. Fundamentals of the theory of spectra of atoms and ions (Moscow: Nauka, 1983) [in Russian]

9. U.I. Safronova, V.S. Senashenko, Theory of spectra of multiply charged ions (Moscow: Energoatomizdat, 1984) [in Russian]

10. M.A. Brown, A.D. Gurchumelia, W.I. Safronov. Relativistic theory of the atom (Moscow: Nauka, 1984) [in Russian]

11. L.A. Weinstein, V.P. Shevelko, Structure and characteristics of ions in hot plasma (Moscow: Nauka, 1986) [in Russian]

12. G.I. Tachiev, C.F. Fischer, Astronomy \& Astrophysics, 385(2), 716-723 (2002) DOI: 10.1051/0004-6361:20011816

13. L. Radžiūtè, J. Ekman, P. Jönsson, G. Gaigalas, Astronomy \& Astrophysics, 582(A61), 6 (2015) http://dx.doi.org/10.1051/0004-6361/201526708

14. E. Träbert, Atoms, 2(1), 15-85 doi:10.3390/atoms2010015

15. K. Wang, P. Jönsson, J. Ekman, R. Si, Z.B. Chen, Y.G. Li, ... \& J. Yan, Journal of Quantitative Spectroscopy and Radiative Transfer, 194, 108-112 (2017) https://doi.org/10.1016/j.jqsrt.2017.03.014

16. K. Wang, S. Li, P. Jönsson, N. Fu, W. Dang, X.L. Guo, ... \& R. Si, Journal of Quantitative Spectroscopy and Radiative Transfer, 187, 375-402 (2017) https://doi.org/10.1016/j.jqsrt.2016.10.011

17. K. Wang, R. Si, W. Dang, P. Jönsson, X.L. Guo, S. Li, ... \& D.F. Li, The Astrophysical Journal Supplement Series, 223(1), 3 (2016) http://dx.doi.org/10.3847/0067-0049/223/1/3

18. C.E. Moore, Atomic Energy Levels, Circular of the National Bureau of Standards (Superintendent of Documents, US Government Printing Office, Washington, 25, 1949)

19. S. Bashkin, J.O. Stoner, Atomic energy levels and Grotrian diagrams: Hydrogen I-phosphorus XV (North-Holland Publ. Comp., 1975) ISBN: 0-7204-0322-7

20. B.A. Nadykto, Physics-Uspekhi, 36(9), 794 (1993) [in Russian] https://doi.org/10.1070/PU1993v036n09ABEH0023 07 
21. B.A. Nadykto, O.B. Nadykto, Questions of atomic science and technology. Series Theoretical and Applied Physics, 1, 3-12 (2007) [in Russian]

22. B.A. Nadykto, O.B. Nadykto, Questions of atomic science and technology. Series Theoretical and Applied Physics, 1, 13-50 (2007) [in Russian]

23. B.A. Nadykto, O.B. Nadykto, Questions of atomic science and technology. Series Theoretical and Applied Physics, 1, 51-99 (2007) [in Russian] 